\title{
The Effects of Relative Strength of USD and Overnight Policy Rate on Performance of Malaysian Stock Market - Evidence from 1980 through 2015
}

\author{
Abdul Razak Abdul Hadi', Eddy Tat Hiung Yap', Zalina Zainudin¹
}

ABSTRACT

KEY WORDS:

JEL Classification:

\begin{abstract}
The study is carried out with the objective of testing the efficient market hypothesis (EMH) at the semistrong form level. As such, the study employs two publicly available data variables - the exchange rate (RM/USD) and short-term interest rate as proxied by the overnight policy rate (OPR). The extent to which these variables influenced the performance of Bursa Malaysia (KLCl) over the past 35 years, from January 1980 to June 2015, is examined. Using monthly data, the entire study period is divided into three subperiods - the full sample period, the sample period that excludes the duration of capital control and the sample period of FBMKLCI (from July 2009 to June 2015). Deploying the Johansen-Juselius cointegration test, the study shows the presence of a long-run equilibrium relationship between $\mathrm{KLCl}$ and the two control variables over the full sample period and sample period, excluding the period of capital control. From the long-run regression, the effect of OPR on Bursa Malaysia is consistent over all three subperiods. This is a clear indication that the interest rate regime has a significant influence on Bursa Malaysia. Interestingly, there is no equilibrium relationship, and dynamic relationships exist between FBMKLCl and the two explanatory variables over the FBMKLCI sample period. These findings support our notion that Bursa Malaysia is unquestionably semistrong form efficient. It is now evident that FBMKLCl is the most exogenous variable of all.
\end{abstract}

Stock Market Performance, Efficient Market Hypothesis, Macroeconomic Variables, Vector Error Correction Modeling, Johansen-Juselius cointegration test

G12, G14

${ }^{1}$ Universiti Kuala Lumpur Business School, Universiti Kuala Lumpur, Malaysia

\section{Introduction}

This article is driven by the motivation to investigate the validity of the efficient market hypothesis (EMH) $\underline{\mathbf{0}}$ on Bursa Malaysia over a study period spanning Janu-

Correspondence concerning this article should be addressed to: Abdul Razak Abdul Hadi, Universiti Kuala Lumpur Business School, Universiti Kuala Lumpur, 1016 Jalan Sultan Ismail, 50250 Kuala Lumpur, Malaysia.E-mail: abdrazak@unikl.edu.my ary 1980 through June 2015. We re-examine the informational efficiency of the Malaysian stock market to determine to what extent Bursa Malaysia is detrimentally affected by a number of economic downturns over this observed period. Aside from the Asian debt crisis of 1997-1998, the 2008 U.S. subprime mortgage crisis has been the worst recession since the Great Depression in 1929. This study is considered unique, as it explores the theoretical links among three different 
financial markets, namely, the capital market, money market and foreign exchange market. The Malaysian exchange rate (RM/USD) is set as an independent variable along with short-term interest rates, as proxied by the overnight policy rate (OPR).

Stock market indices are leading indicators of the general economy, as such indices are deemed a barometer of the state of the economy due to their sensitivity and susceptibility to both information and disinformation. As the current stock market prices factor into the future outlook of the macro economy, industry and the company in particular, they bear important policy implications as a predictor of the economy, as market prices change faster than the publishing of economic data. There have been extensive studies on stock market efficiency with various permutations performed, but there are still no conclusive results to validate the efficient market hypothesis (EMH) (Fama, 1965), and various interpretations on the efficiency of stock markets persist.

Market efficiency has important repercussions for investors who seek to identify assets to invest in the equity markets. If the equity market is efficient, attempts to find mispriced assets to make excess returns would not yield any extraordinary returns. In efficient markets, asset prices reflect the best estimate that investors make with regard to the expected risk and the expected return of the assets. Therefore, there are no undervalued assets offering higher than expected returns or overvalued assets offering lower than expected returns, as all assets in the market will be appropriately priced, offering an optimal reward to risk in an efficient market. Conversely, in inefficient markets, investors can enhance returns by identifying and investing in mispriced assets. The EMH thus functions as a theoretical and predictive model of the operations of the financial markets.

\section{Literature Review}

\section{Malaysian Stock Market}

Overall, research on Asian stock market efficiency has shown mixed results. The EMH has been frequently rejected in these studies, where markets are found to be inefficient when using daily frequency data. However, these studies show that stock prices adhere to the $\mathrm{EMH}$ when lower-frequency data, such as monthly and quarterly data, are used. Most of these studies utilize the variance ratio (VR) test of Lo and MacKinlay (1988; 1989). However, as pointed out by Wright (2000), nonparametric-based tests are more effective than traditional VR tests, which may provide inconsistent results for different sampling periods. To consider this problem, some studies have used the multiple VR (MVR) test of Chow and Denning (1993), which allows for testing the behavior of stock prices through different intervals of time.

A number of studies analyzed the EMH for Asian stock markets, with the results showing that Asian stock markets are characterized by a certain degree of predictability, especially when daily data are considered (Buguk \& Brorsen, 2003; Chang \& Ting, 2000; Chang, Arauio-Lima, \& Tabak, 2004; Fifield \& Jetty, 2008; Hoque, Jae, \& Pyun, 2007; Hung, 2009; Karemera, Ojah, \& Cole, 1999; Lagoarde \& Lucey, 2008). However, applying the conventional VR test in cases when data are not normally distributed may lead to high acceptance rates for the null hypothesis of random walk. To overcome this problem, some authors have preferred using MVR tests. The use of MVR tests provides more robust results given that it also considers the presence of heteroscedasticity. On the other hand, as pointed out by Charles and Darne (2009), splitting a sample of data into subperiods and applying the MVR test to each subsample may lead to asymmetric results, where the EMH may be found only in more recent periods. This may be explained by the evolving regulatory environment of stock markets, such as the liberalization of trading restrictions. Using Wright's nonparametric test, Kim and Shamsuddin (2008) and Charles and Darne (2009) found higher rates of rejection of the EMH, i.e., market inefficiency.

It is evident from the review of the literature that a mix of different results has been achieved using different methods, different datasets and different time periods. Ongoing liberalization processes and the removal of trading restrictions taking place in ASEAN stock markets may explain to a certain extent the asymmetrical results.

\section{Exchange Rates and Short-Term Interest Rates}

In studies on country exchange rates, for export-dominant countries, there is a negative relationship, as home currency appreciation would lower the export coun- 
try's competitiveness due to higher selling prices in the destination country. For import-dominant countries, there is a positive relationship, as demonstrated by Mukherjee and Naka (1995), Maysami and Koh (2000) and Ibrahim and Aziz (2003), with the assertion that home currency appreciation reduces overall costs.

In studies of inflation, there is a positive relationship between the consumer price index and stock market returns, as reported by Abdullah and Hayworth (1993), Khil and Lee (2000), Ibrahim and Aziz (2003), Shabri, Meera, Aziz and Ibrahim (2001), Ibrahim and Aziz (2003), because stocks are used as hedges against inflation. There is, however, a negative relationship between the consumer price index and stock market returns, as shown by Fama and Schwert (1977), Fama (1970), Schwert (1981), Solnik (1983), Gultekin (1983), Geske and Roll (1983), Chen, Roll and Ross (1986), DeFina (1991) and Mukherjee and Naka (1995), due to an increase in the cost of production and an increase in the nominal risk-free rate of return.

In studies of money supply, theoretically, there is a negative relationship between money supply and stock returns because an increase in money supply may raise expectations of inflation and thus raise the interest rate, which would reduce corporate profitability. However, a positive relationship is shown between money supply and stock returns by Abdullah and Hayworth (1993) and Mukherjee and Naka (1995) because an increase in money supply increases liquidity in the economy (creating motivation in the economy), leading to lower interest rates.

\section{Methodology}

The EMH was widely accepted until the 1990s, when behavioral economists provided alternative methods for analyzing the stock market. Empirical analyses have consistently found problems with the EMH, as stocks with low price-earnings ratios are found to be outperforming other stocks (Sembiring, Rahman, Effendi, \& Sudarsono, 2016). Alternative theories have proposed that cognitive biases cause these inefficiencies, leading investors to purchase overpriced growth stocks rather than value stocks. Although the EMH has become controversial because substantial and lasting inefficiencies are observed, Beechey (2000) considers that it remains a worthwhile starting point for studies on stock market performance.
The efficient market hypothesis emerged as a prominent theory in 1965 when Fama (1965) published his dissertation arguing for the random walk hypothesis, with Samuelson (1965) subsequently publishing a proof for an enhanced version of the EMH. Fama (1970) reviewed both the theory and the evidence for the EMH to include the definitions for three forms of financial market efficiency: weak, semistrong and strong.

\section{Model Description}

The vector autoregressive (VAR) method is the estimation technique used in this study and encompasses Johansen-Juselius multivariate cointegration, the vector error correction model (VECM), impulse response function (IRF) and variance decomposition (VDC). To investigate the theoretical relationship between the stock market and the two explanatory variables, the following model is developed:

\section{$\mathrm{STKMKT}=\mathrm{f}(\mathrm{EXRT}, \mathrm{OPR})$}

where

STKMKT = Malaysian main board counters (proxied by FBMKLCI)

EXRT $=$ Exchange rate $(\mathrm{RM} / \mathrm{USD})$

OPR = Overnight policy rate (Proxy for short term interest rates)

The mathematical expression of the model is as follows:

$\mathrm{STKMKT}=\beta_{0}+\beta_{1} \mathrm{EXRT}+\beta_{2} \mathrm{OPR}+\mu_{\mathrm{t}}$

where

$\mu_{\mathrm{t}}=$ Error term

$\mathrm{B}_{0}=$ Intercept on the vertical axis

This study takes 35 years of observations, spanning from January 1980 until June 2015. In evaluating the statistical relationship between FBMKLCI and the two control variables, Johansen-Jeselius cointegration procedures (1990) are mobilized.

The cointegration test is a statistical concept introduced by Granger (1981), Granger and Weiss (1983) and Engle and Granger (1987), which has received wide attention and is beginning to be applied to test the validity of various theories and models. Cointegration is an econometric technique for testing the correlation 
between nonstationary time-series variables. In this approach, two variables are cointegrated when a linear combination of the two is stationary, even though each variable is nonstationary on its own or at level (Sanusi, Meyer, \& Ślusarczyk, 2017). Usually, when X and $\mathrm{Y}$ variables are nonstationary, it is expected that a linear combination of two variables would also be nonstationary (Hussain, Salem, Rashid, \& Kamarudin, 2019). However, this notion has been proven incorrect by Engle and Granger (1987). According to Granger (1981) and Engle and Granger (1987), the components in vector $\mathrm{X}_{\mathrm{t}}$ are cointegrated at $d, b$ degree if the following holds:

i) All components of $X_{t}$ are $I(d)$.

ii) There is a nonzero vector $\beta=\left(\beta_{1}, \beta_{2}, \ldots, \beta_{n}\right)$, so the linear combination of $\beta X_{t}=\beta_{1} X_{1 t}+\beta_{2} X_{2 t}+\ldots+$ $\beta \mathrm{nX}_{\mathrm{nt}}$ will be cointegrated at $d, b$ degree, where $b>0$. The vector $\beta$ is the cointegration vector. Note that $d$ is the number of differencing vectors, while $b$ represents the number of cointegrating vectors.

To avoid the problem of nonstationarity, it is necessary to make use of first (or higher) differentiated data. Such differencing, however, may result in a loss of precious data points on the long-run characteristics of the time-series data. However, Engle and Granger (1987) show that if there is an equilibrium relationship between such variables, then the disequilibrium error should fluctuate around zero, i.e., the error terms should be stationary. The unit root test is important in determining the stationarity of time-series data. Whether the variables tested have the tendency to return to their long-term trend after a shock (i.e., it is stationary) or exhibits a random walk pattern (i.e., it has a unit root) is an important question to be answered prior to any further data analysis, as the latter would suggest a spurious regression relationship. This paper uses the augmented Dickey Fuller test (ADF):

$\Delta \mathrm{X}_{\mathrm{t}}=\lambda_{0}+\lambda_{1} \mathrm{~T}+\lambda_{2} \mathrm{X}_{\mathrm{t}-1}+\Sigma \lambda_{\mathrm{i}} \Delta \mathrm{X}_{\mathrm{t}-\mathrm{i}}+\varepsilon_{\mathrm{t}}$

where $\mathrm{i}=1,2,3 \ldots \mathrm{k}$

The hypotheses being tested are as follows:

$\mathrm{H}_{0}: \lambda_{2}=0$ (the data are not stationary and contain the unit root)

$\mathrm{H}_{1}: \lambda_{2}<0$ (the data are stationary and do not contain the unit root)
Once this requirement is met, $\mathrm{X}$ and $\mathrm{Y}$ variables are said to be cointegrated, and the vector error correction model (VECM) can be pursued. The VECM is a restricted vector autoregressive (VAR) method that involves Johansen-Juselius multivariate cointegration. The VECM restricts the long-run behavior of the endogenous variables to converge to their cointegrating relationship while allowing for short-run adjustments. The VECM would allow us to separate short-term from long-term relationships. The VAR model is expressed as follows:

$\mathrm{X}_{\mathrm{t}}=\mathrm{A}_{0}+\sum_{\mathrm{k}=1}^{\mathrm{p}} \mathrm{A}_{\mathrm{k}} \mathrm{X}_{\mathrm{t}-\mathrm{k}}+e_{\mathrm{t}}$

where

$\mathrm{X}_{\mathrm{t}}$ is in the form of the $\mathrm{nx} 1$ vector of variables

$A_{0}$ is an $n \times 1$ vector of constant terms

$A_{k}$ is an $n \times n$ matrix of coefficients

$e_{t}$ is an $n \times 1$ vector of error terms

The results from the cointegration test will expose the long-term relationships among the variables involved. The specifications of their short-run dynamics will be represented by the VAR model. If the variables are nonstationary and are not cointegrated, the VAR model above (in first differences) will be used. If, on the other hand, the variables are cointegrated, the VECM model (a level VAR) is used (Engel \& Granger 1987).

The study also applies the ordinary least squares (OLS) method, which is subjected to classical normal linear regression assumptions. These critical assumptions are as follows: a) time-series data must be stationary, b) the residual or error term must be homoscedastic, c) residuals are independent of one another or there is no autocorrelation between residuals, d) residual distribution is normal, and e) independent variables are not related to one another or there is an absence of multicollinearity. To ensure that all statistical findings are valid, the assumptions must be observed. For this reason, diagnostic tests consisting of the augmented Dickey Fuller unit root test, moments of specification test/White test, Durbin-Watson test, Anderson-Darling test and variance inflation technique are carried out. In investigating the relationship between STKMKT and the four tested variables, the study expects unidirectional causality from the three variables to STKMKT. 


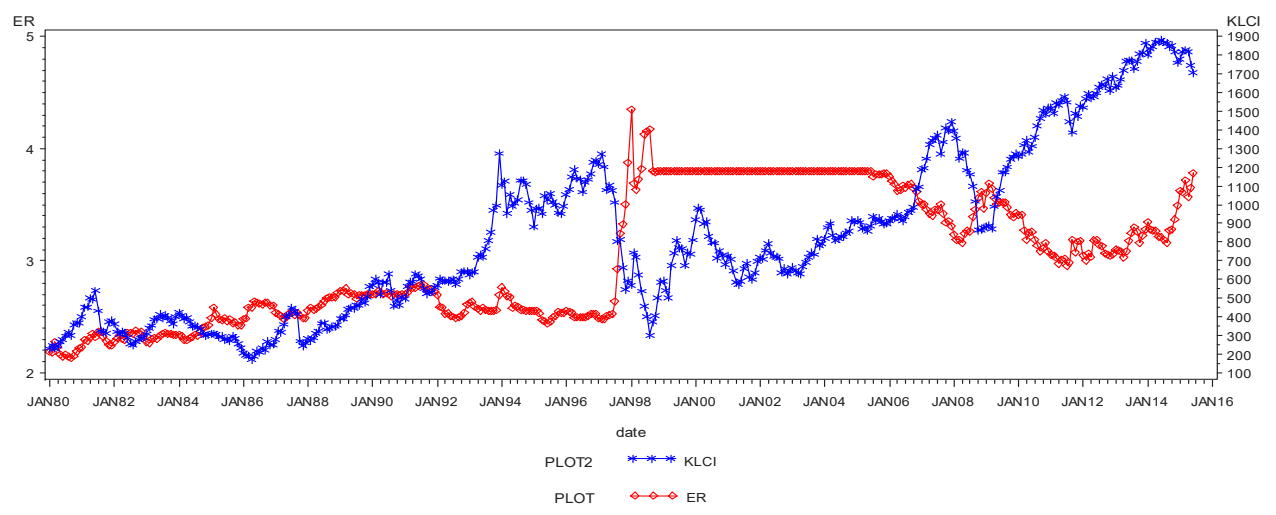

Figure 1. Movements of Exchange Rates and KLCl

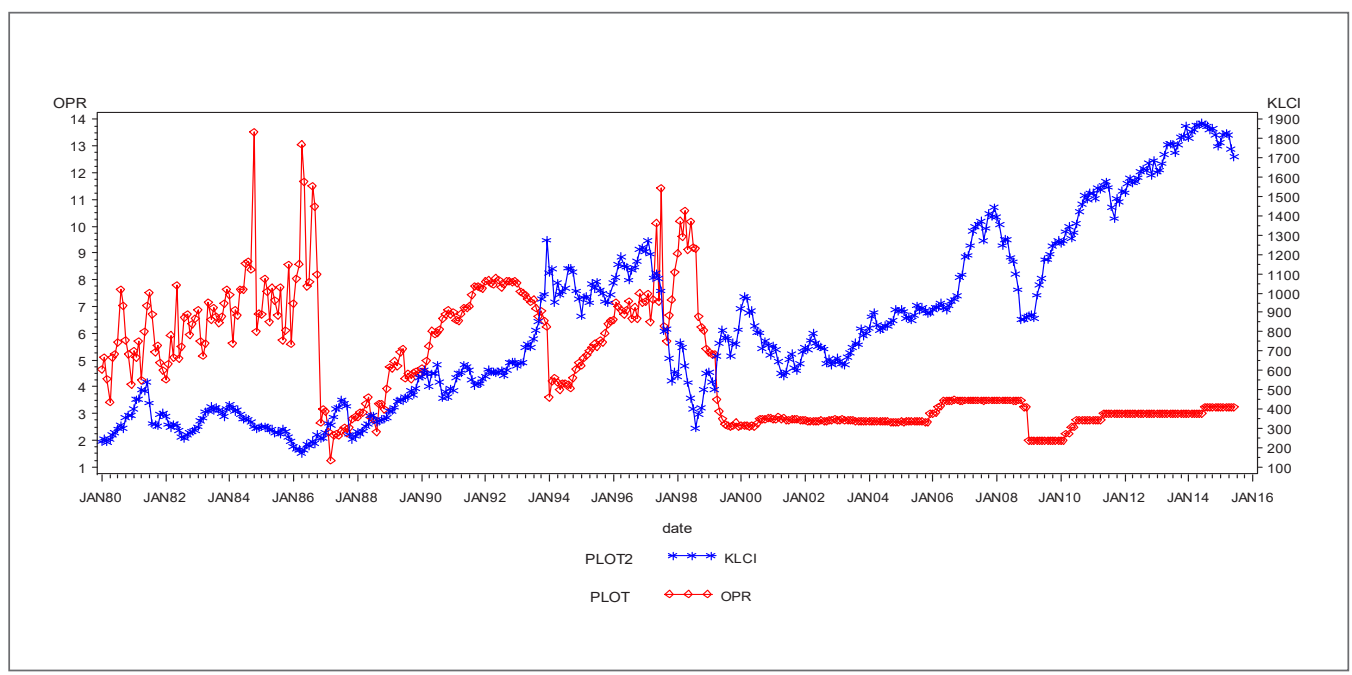

Figure 2. Movements of Overnight Policy Rates and KLCl

First, the study will perform unit root tests on all time-series variables, followed by the Johansen-Juselius cointegration test and Granger causality test within vector error correction modeling. To examine the dynamic interaction between the variables, the study employs variance decomposition (VDC).

\section{Empirical Results}

Given the main aim is based on three variables of concern: exchange rate, overnight policy rate and the KLCI. It is thus important to evaluate the trend for movement of these three variables. The movement of exchange rates and the KLCI is presented in figure 1. 
Table 1. Unit Root Tests

At Level

Null: Presence of Unit Root (Nonstationary)

\begin{tabular}{lccc}
\hline & \multicolumn{2}{c}{ P-value } \\
\cline { 2 - 4 } Approach & Full Sample Period & Period without Capital Control & Period of FBMKLCl \\
\hline LLC & 0.4781 & 0.7381 & 0.0217 \\
IPS & 0.2192 & 0.2953 & 0.3856 \\
ADF & - & - & 5.0000 \\
PP & 0.0278 & 0.0151 & 0.2881 \\
\hline
\end{tabular}

Note:

LLC: Levin, Lin and Chu

IPS: Im, Pesaran and Shin W-test

ADF: Augmented Dickey-Fuller chi-squared test

PP: Phillips-Perron chi-squared test

\section{At First Difference}

Null: Presence of Unit Root (Nonstationary)

\begin{tabular}{|c|c|c|c|}
\hline \multirow{2}{*}{ Approach } & \multicolumn{3}{|c|}{ P-value } \\
\hline & Full Sample Period & Period without Capital Control & Period of $\mathrm{FBMKLCl}$ \\
\hline LLC & $<0.0001^{*}$ & $<0.0001^{*}$ & $<0.0001^{*}$ \\
\hline IPS & $<0.0001^{*}$ & $<0.0001^{*}$ & $<0.0001^{*}$ \\
\hline ADF & - & - & - \\
\hline PP & $<0.0001^{*}$ & $<0.0001^{*}$ & $<0.0001^{*}$ \\
\hline
\end{tabular}

Note:

LLC: Levin, Lin and Chu

IPS: Im, Pesaran and Shin W-test

ADF: Augmented Dickey-Fuller chi-squared test

PP: Phillips-Perron chi-squared test

The trend of movement between the overnight policy rate and the KLCI is further presented in figure 2 as an initial graphical representation.

This study employs a group unit root test on the three time-series data. The p-value is used to determine the significance level of the hypothesis testing. The time series under consideration should be integrated in the same order before the study can proceed to the Johansen-Juselius cointegration test. Table 1 presents the test results from the ADF and PP tests on each variable for each country at the level and first difference, respectively.

The test results show the acceptance of the null hypothesis, indicating that all time-series variables are nonstationary at level. On the other hand, all null hypotheses on the first differenced data series are rejected, 
Table 2. Optimal Lag Length

\begin{tabular}{ccccccc}
\hline Lag & LogL & LR & FPE & AIC & SC & HQ \\
\hline 0 & -4315.428 & NA & 188848.7 & 20.66233 & 20.69130 & 20.67378 \\
1 & -2224.391 & 4142.053 & 8.906723 & 10.70044 & $10.81629^{*}$ & 10.74623 \\
2 & -2204.316 & 39.47719 & 8.447113 & 10.64745 & 10.85019 & $10.72759^{*}$ \\
3 & -2192.123 & 23.80275 & 8.319189 & 10.63217 & 10.92180 & 10.74666 \\
4 & -2180.815 & 21.91401 & 8.228067 & 10.62112 & 10.99764 & 10.76997 \\
5 & -2178.561 & 4.335210 & 8.498429 & 10.65340 & 11.11680 & 10.83659 \\
6 & -2165.123 & 25.65416 & 8.320507 & 10.63217 & 11.18246 & 10.84971 \\
7 & -2151.595 & 25.63137 & 8.143041 & 10.61050 & 11.24768 & 10.86239 \\
8 & -2136.069 & $29.19583^{*}$ & $7.893763^{*}$ & $10.57928^{*}$ & 11.30335 & 10.86552 \\
\hline
\end{tabular}

Note:

SC: Schwarz information criterion

AIC: Akaike information criterion

FPE: Final prediction error

HQ: Hannan-Quinn information criterion

LR: sequential modified LR test statistic (each test at the $5 \%$ level)

Table 3. Eigenvalues

\begin{tabular}{lccc}
\hline \multirow{2}{*}{ Approach } & \multicolumn{3}{c}{ Number of Cointegrating Equations } \\
\cline { 2 - 4 } & Full Sample Period & Period without Capital Control & Period of FBM KLCI \\
\hline Trace test (5\%) & 0 & $\mathbf{1}$ & 0 \\
Trace test (1\%) & 0 & 0 & 0 \\
Max-eigen test (5\%) & $\mathbf{1}$ & $\mathbf{1}$ & 0 \\
Max-eigen test (1\%) & 0 & 0 & 0 \\
\hline
\end{tabular}

indicating that all data series under consideration are stationary at first difference. From the test results above, it is now obvious that all investigated variables are stationary at the same order or integrated at first difference, I(1). To determine the optimum lag length, the study uses AIC and SC statistics. The test results in Table 2 show that the best model is obtained with the utilization of lag 2. To test the significance of the error correction term ("ect") in each individual model above, the p-value is reported to indicate the level of significance.

The Johansen-Juselius cointegration test is used to determine the number of cointegrating vectors. Johansen (1988) suggests two statistical tests to determine the cointegration rank, namely, lamda trace and lamda max. The results of this cointegration analysis are summarized in Table 3. The lamda trace and lamda max 
Table 4. Vector Error Correction Estimates (Granger Causality Test)

\begin{tabular}{|c|c|c|c|}
\hline Cointegrating Eq: & $\begin{array}{c}\text { CointEq1 } \\
\text { Standard Errors in ( ) } \\
\text { t-Statistics in [ ] }\end{array}$ & & \\
\hline $\mathrm{KLCl}(-1)$ & 1.000000 & & \\
\hline \multirow[t]{3}{*}{ ER_RM_USD_(-1) } & 1744.591 & & \\
\hline & $(656.164)$ & & \\
\hline & [ 2.65877] & & \\
\hline \multirow[t]{3}{*}{ OLR_OPR(-1) } & 896.5935 & & \\
\hline & $(172.165)$ & & \\
\hline & {$[5.20775]$} & & \\
\hline C & -10306.61 & & \\
\hline Error Correction: & $\mathrm{D}(\mathrm{KLCl})$ & D(ER_RM_USD_) & D(OLR_OPR) \\
\hline \multirow[t]{3}{*}{ CointEq1 } & -0.002337 & $2.37 \mathrm{E}-06$ & -0.000126 \\
\hline & $(0.00154)$ & $(2.1 \mathrm{E}-06)$ & (2.7E-05) \\
\hline & {$[-1.51280]$} & [1.10669] & {$[-4.65243]$} \\
\hline \multirow[t]{3}{*}{$\mathrm{D}(\mathrm{KLCl}(-1))$} & 0.044925 & -0.000128 & -0.001260 \\
\hline & $(0.05087)$ & (7.1E-05) & $(0.00089)$ \\
\hline & [0.88310] & {$[-1.80891]$} & {$[-1.41457]$} \\
\hline \multirow[t]{3}{*}{ D(ER_RM_USD_(-1)) } & -26.92680 & 0.069751 & 0.607196 \\
\hline & $(36.8332)$ & $(0.05108)$ & $(0.64489)$ \\
\hline & {$[-0.73105]$} & {$[1.36561]$} & {$[0.94156]$} \\
\hline \multirow[t]{3}{*}{ D(OLR_OPR(-1)) } & -1.359181 & -0.002320 & -0.233088 \\
\hline & $(2.68212)$ & $(0.00372)$ & $(0.04696)$ \\
\hline & {$[-0.50676]$} & {$[-0.62377]$} & {$[-4.96362]$} \\
\hline \multirow[t]{3}{*}{ C } & 3.366991 & 0.003991 & -0.002753 \\
\hline & $(2.41707)$ & $(0.00335)$ & $(0.04232)$ \\
\hline & [1.39301] & [1.19065] & {$[-0.06505]$} \\
\hline R-squared & 0.013013 & 0.021982 & 0.132267 \\
\hline Adj. R-squared & 0.003590 & 0.012645 & 0.123983 \\
\hline Sum sq. resids & 1026768. & 1.974414 & 314.7448 \\
\hline S.E. equation & 49.50272 & 0.068646 & 0.866707 \\
\hline F-statistic & 1.381044 & 2.354376 & 15.96687 \\
\hline Log likelihood & -2253.575 & 536.6959 & -538.4600 \\
\hline Akaike AIC & 10.65365 & -2.508000 & 2.563491 \\
\hline Schwarz SIC & 10.70141 & -2.460243 & 2.611247 \\
\hline \multicolumn{2}{|c|}{ Determinant resid covariance (dof adj.) } & 7.954825 & \\
\hline \multicolumn{2}{|l|}{ Determinant resid covariance } & 7.676710 & \\
\hline \multicolumn{2}{|l|}{ Log likelihood } & -2236.986 & \\
\hline \multicolumn{2}{|l|}{ Akaike information criterion } & 10.63673 & \\
\hline \multicolumn{2}{|l|}{ Schwarz information criterion } & 10.80865 & \\
\hline
\end{tabular}


Table 5. Variance Decomposition

\begin{tabular}{|c|c|c|c|c|}
\hline \multicolumn{5}{|c|}{$\begin{array}{l}\text { Variance Decomposition of } \\
\text { KLCl: }\end{array}$} \\
\hline Period & S.E. & $\mathrm{KLCl}$ & ER_RM_USD_ & OLR_OPR \\
\hline 1 & 48.87666 & 100.0000 & 0.000000 & 0.000000 \\
\hline 2 & 70.83862 & 99.92184 & 0.026438 & 0.051720 \\
\hline 3 & 92.88240 & 99.94825 & 0.021612 & 0.030138 \\
\hline 4 & 111.0202 & 99.90495 & 0.023878 & 0.071169 \\
\hline 5 & 127.4561 & 99.84465 & 0.028703 & 0.126648 \\
\hline 6 & 142.1758 & 99.73921 & 0.037872 & 0.222917 \\
\hline 7 & 155.7442 & 99.60565 & 0.049254 & 0.345099 \\
\hline 8 & 168.3510 & 99.44427 & 0.062692 & 0.493036 \\
\hline 9 & 180.2078 & 99.26264 & 0.077609 & 0.659752 \\
\hline 10 & 191.4393 & 99.06421 & 0.093692 & 0.842094 \\
\hline
\end{tabular}

Variance Decomposition of ER_RM_USD_:

\begin{tabular}{ccccc} 
Period & S.E. & KLCI & ER_RM_USD_ & OLR_OPR \\
\hline 1 & 0.068116 & 7.770082 & 92.22992 & 0.000000 \\
2 & 0.101276 & 10.30198 & 89.69752 & 0.000497 \\
4 & 0.124595 & 14.06084 & 85.78240 & 0.156755 \\
5 & 0.144430 & 16.39495 & 83.34465 & 0.260396 \\
6 & 0.162454 & 17.92066 & 81.73594 & 0.343396 \\
7 & 0.178952 & 18.95172 & 80.58967 & 0.458609 \\
8 & 0.194259 & 19.70413 & 79.70509 & 0.590784 \\
9 & 0.208626 & 20.25794 & 79.00765 & 0.734407 \\
10 & 0.222231 & 20.67790 & 78.43527 & 0.886834 \\
\hline
\end{tabular}

\section{Variance Decomposition of} OLR_OPR:

\begin{tabular}{ccccc} 
Period & S.E. & KLCI & ER_RM_USD_ & OLR_OPR \\
\hline 1 & 0.866921 & 0.004354 & $8.08 \mathrm{E}-05$ & 99.99556 \\
2 & 1.030347 & 0.593290 & 0.043250 & 99.36346 \\
3 & 1.151518 & 0.742103 & 0.096649 & 99.16125 \\
4 & 1.252453 & 0.950395 & 0.084097 & 98.96551 \\
5 & 1.331677 & 1.083525 & 0.075976 & 98.84050 \\
6 & 1.395186 & 1.190085 & 0.078606 & 98.73131 \\
7 & 1.447458 & 1.267815 & 0.096306 & 98.63588 \\
9 & 1.490725 & 1.329611 & 0.132034 & 98.53835 \\
10 & 1.526817 & 1.378143 & 0.186760 & 98.43510 \\
\hline
\end{tabular}


statistics indicate the existence of cointegration between variables. The null hypothesis of no cointegrating vector $(r=0)$ is rejected at the $5 \%$ significance level on all lags tested (1,2 and 3). Since lamda trace and lamda max are greater than their respective critical values, we conclude that there are at least four cointegrating vectors for the time-series variables in the system. This cointegrating vector or $r$ is the variable that pulls all three variables in the equation to be cointegrated in the long run. In other words, $r$ indicates the number of cointegrating relationships (Masih \& Masih, 1996).

Table 4 shows the results of all VECM estimates. However, this paper focuses only on the FBMKLCI model, in which ect in VECM (1) is significant at the $5 \%$ level. ect has to be negative in value or its value must lie within the range of 0.00 to $-1.00(0.00>$ ect $>-$ $1.00)$. Since the value of ect from VECM (1) equals -0.002337 , we can conclude that there is a significant long-run relationship at the $10 \%$ level (t-statistic: 1.5128) between FBMKLCI and the other two variables, namely, ER and OPR. Furthermore, there is an approximately $0.2 \%$ speed of adjustment toward equilibrium made by FBMKLCI in the system. This is considered a moderate adjustment process and could be attributed to the current scenario in the global commodity markets. A higher speed of adjustment is preferred because a statistically reliable model should converge to its steady state at a faster rate. This finding substantiates our theoretical model that FBMKLCI is the endogenous variable.

From the cointegrating equation at the top of Table 5 , the parameter estimate of each explanatory variable also shows a negative relationship with FBMKLCI in the long run (takes the opposite sign). Any increase in EXRT and OPR will directly dampen the performance of FBMKLCI. With regard to policy implications, fund managers and investors will benefit from the empirical findings of this study. It is now evident that there are significant relationships between these two financial markets (foreign exchange market and money market) and Bursa Malaysia. With the right set of information, market players are able to strategize their portfolios to maximize their potential return with a given level of risk.

\section{Conclusion}

The aim of this paper is to test the validity of the EMH in the context of the Bursa Malaysian main market over three tested subperiods. From the findings above, we can conclude with a high degree of certainty that there is a long-run equilibrium relationship between FBMKLCI and the two control variables (exchange rate and overnight policy rate) over the full sample period and subperiods, excluding the period of capital control. From the long-run regression, the effect of the overnight policy rate on Bursa Malaysia is consistent over all three subperiods. This is a clear indication that the interest rate regime has a significant influence on Bursa Malaysia. This finding is consistent with that of Graham and Harvey (2018) that market risk premiums influence stock market performance. Interestingly, there is no long-run relationship between FBMKLCI and the two control variables over the FBMKLCI sample period. However, from the analysis of dynamic interactions via variance decomposition during the postsample period (see Table 5), the study reveals that FBMKLCI is the most exogenous variable of all. As such, Bursa Malaysia is unquestionably a leading economic indicator. Future studies should incorporate the most recent datasets and continue to shed light on this EMH.

\section{References}

Abdullah, D. A. \& Hayworth, S. C. (1993). Macroeconometrics of stock price fluctuations. Quarterly Journal of Business and Economics, 32, 50-67.

Beechey M.G.D \& Vickrey J. (2000). The Efficient Markets Hypothesis: A Survey. Reserve Bank of Australia.

Buguk, C. \& Brorsen, B. W. (2003). Testing weak-form market efficiency: evidence from the Istanbul stock exchange. International Review of Financial Analysis, 12, 579-90.

Chang, K. P. \& Ting, K. S. (2000). A variance ratio test of the random walk hypothesis for Taiwan's stock market. Applied Financial Economics, 20, 525-32.

Chang, E. J., Arauio-Lima, E. J. \& Tabak, B.M. (2004). Testing for predictability in emerging equity markets. Emerging Market Review, 5, 295-316.

Charles, A. \& Darne, O. (2009). The random walk hypothesis for Chinese stock markets: evidence from variance ratio tests, Economic Systems, 33, 117-26.

Chen, N. F., Roll, R., \& Ross, S. A. (1986). Economics forces and the stock market, Journal of Business, 59, 383-403. 
Chow, V. K., \& Denning, K. D. (1993). A simple multiple variance ratio test, Journal of Econometrics, 58, 385-401.

DeFina, R. P. (1991). Does Inflation Depress the Stock Market? Business Review-Federal Reserve Bank of Philadelphia, 1991(10-11), 3-12.

Engle, R. F., \& Granger, G. W. J. (1987). Co-integration and error correction: Representation, estimation and testing. Econometrica, 55(2), 251-276.

Fama, E. F. (1965). The Behavior of Stock Market Prices. Journal of Business, 38, 34-105.

Fama, E. F. (1970). Efficient Capital Markets: A Review of Theory and Empirical Work. Journal of Finance, 25 (2), 383-417.

Fama E. F. \& Schwert, W. G. (1977). Asset returns and inflation. Journal of Financial Economics, 5, 115-146.

Fifield, S. G. M., \& Jetty, J. (2008). Further evidence on the efficiency of the Chinese stock markets: a note. Research in International Business and Finance, 22, 351-61.

Geske, R., \& Roll, R. (1983). The fiscal and monetary linkage between stock returns and inflation. Journal of Finance, 38, 1-33.

Graham, J. R., \& Harvey, C. R. (2018). The Equity Risk Premium in 2018. Available at https://ssrn.com/ abstract $=3151162$

Granger, C. W. J. (1981). Some properties of time series data und their use in econometric model specification. Journal of Econometrics, 16(1), 121-130.

Granger, C. W. J., \& Weiss, A. (1983). Time series of error correction models in studies in Economics Time Series and Multivariate Statistics. New York, NY: Academic Press.

Gultekin, N. B. (1983). Stock market returns and inflation. Evidence from other countries. The Journal of Finance, 38, 49-65.

Hoque, H., Jae, H. K., \& Pyun, C. S. (2007). A comparison of variance ratio tests of random walk: a case of Asian emerging stock markets. International Review of Economics and Finance, 16, 488-502.

Hung, J. C. (2009). Deregulation and liberalization of the Chinese stock market and the improvement of market efficiency. The Quarterly Review of Economics and Finance, 49, 843-57.

Hussain, H. I., Salem, M. A., Rashid, A. Z. A., \& Kamarudin, F. (2019) Environmental Impact of Sectoral Energy Consumption on Economic Growth in Malaysia: Evidence from ARDL Bound Testing Approach, Ekoloji, 28(107), 199 - 210.

Ibrahim M.H. \& Aziz H. (2003). Macroeconomic variables and the Malaysian equity market: A view through rolling subsamples. Journal of Economic Studies, 30, 6 - 27

Johansen, S. (1988). Statistical Analysis of Conintegration Vectors. Journal of economic Dynamics and Control, 12, 231-254.

Karemera, D., Ojah, K. \& Cole, A. J. (1999) Random walks and market efficiency tests: evidence from emerging equity markets. Review of Quantitative Finance and Accounting, 13, 171-88.

Kim, H. J., \& Shamsuddin, A. (2008). Are Asian stock markets efficient? Evidence from new multiple variance ratio tests. Journal of Empirical Finance, $15,518-32$.

Khil, J., \& Lee, B. S. (2000). Are comman stocks a good hedge against inflation? Evidence from the Pacific-rim countries. Pacific-Basin Finance Journal, 8 (3-4), 457-482.

Lagoarde, S. T. \& Lucey, B. M. (2008) Efficiency in emerging markets: evidence from the MENA region. International Financial Markets, Institutions and Money, 18, 94-105.

Lo, A.W. \& MacKinlay, C. A. (1988). Stock market prices do not follow random walk: evidence from a simple specification test. Review of Financial Studies, 1, 41-66.

Lo, A. W. \& MacKinlay, C. A. (1989) The size and power of the variance ratio test in finite samples: a Monte Carlo investigation. Journal of Econometrics, 20, 203-38.

Masih, A., \& Masih, R. (1996). Energy consumption, real income and temporal causality: results from a multi-country study based on cointegration and error-correction modelling techniques. Energy Economics, 18(3), 165-183.

Maysami, R. C. \& Koh, T. S. 2000. A vector error correction model of the Singapore stock market. International Review of Economics and Finance, 9, 79-96.

Mukherjee, T. K. \& Naka, A. (1995). Dynamic relations between macroeconomic variables and the japanese stock market: an application of a vector error correction model. The Journal of Financial Research, 18, 223-37. 
Sanusi, K. A., Meyer, D., \& Ślusarczyk, B. (2017). The relationship between changes in inflation and financial development. Polish Journal of Management Studies, 16(2), 253-265.

Samuelson, P. (1965). Proof That Properly Anticipated Prices Fluctuate Randomly. Industrial Management Review, 6, 41-49.

Schwert, G.W. (1981). The adjustment of stock prices to information about inflation. The Journal of Finance, 36, 15-29.

Sembiring, F. M., Rahman, S., Effendi, N., \& Sudarsono, R. (2016). Capital asset pricing model in market overreaction conditions: evidence from Indonesia Stock Exchange. Polish Journal of Management Studies, 14(2), 182-191.

Shabri, M., Meera A. K., Aziz, P. P. A., \& Ibrahim, M. (2001). The Relationship Between Stock Returns and Inflation: Evidence From Malaysia and Indonesia. Capital Markets Review, 9(1-2), 129-154.

Solnik, B. (1983). The relation between stock prices and inflationary expectations: the international evidence. Journal of Finance, 38, 35-48.

Wright, J. H. (2000). Alternative variance-ratio tests using ranks and signs. Journal of Business and Economics Statistics, 18, 1-9 